\title{
Transforming Higher Education through Organizational Meditation: A Story of the Executive Learning Series on Equity \& Empowerment
}

\author{
Sonali S. Balajee and Joshua Todd
}

\begin{abstract}
Equity, diversity, and inclusion are frequently on the lips of higher education professionals yet we struggle to infuse these concepts throughout the academy as evidenced in challenges recruiting faculty of color, graduating students of color, and hostile environments reported by students. The authors posit that this is because, to date, most efforts focus on transactional engagements like training and recruitment to achieve racial equity when what is also needed are transformational strategies that fundamentally shift how higher education is envisioned. This article describes the Executive Learning Series on Equity \& Empowerment (ELSEE), which works not to just promote these values but to embody them and transform the academy (and those within it) through a deeper set of interventions, emphasizing the integration of holistic health, spirit based practice, mindfulness, and other practices of decolonization.
\end{abstract}

Keywords: decolonization; racial justice; transformation; leadership

\section{Introduction}

This article could not exist without the spiritual, intellectual, physical, and emotional labor already expended by those who came before us. To mirror the process we use in trainings, which integrates a healing- and trauma-informed approach (Yatchmenoff, n.d), we want to start by acknowledging that labor as well as the violence and loss on which all of higher education and indeed this country are built upon. We honor the indigenous peoples of this land who live here and whose homes were forcibly and violently taken so we could call this land Oregon/United States/ours. We honor the indigenous, African, and Caribbean peoples who were enslaved and murdered in order for our economic system to survive. We acknowledge the broader movements for social, racial, gender, and economic justice that informs our knowledge.

An important part of context-setting is to ground our narrative in a few key terms and processes of focus. At its core, the Executive Learning Series on Equity \& Empowerment (ELSEE) and the Equity \& Empowerment Lens with a racial justice focus (E\&E lens or "the lens”) works to identify the existence and perpetuation of colonization, whiteness, and racism at the individual, institutional, and systemic levels, while also highlighting areas to expand and enhance that are moving in the direction of racial equity (Balajee, 2012. p. 8 \& pp. 62-68). Colonization can be defined as a system and set of processes that define how knowledge, material, and aesthetic resources are organized and distributed, and what ways of being are rewarded and institutionalized. This occurs in three primary ways: the expansion and conquering of land, the elimination of difference (assimilation), and the owning and production of knowledge deeply connected to geography and politics (De Oliveira Andreotti, 2015).

Decolonization, while putting forth clear strategies at times, can be a messy, nonlinear process, which seeks to interrupt harm, deconstruct existing frames and structures that perpetuate harm 
and injustice, and elevates alternate frames and strategies that run counter to the status quo and colonization (De Oliveira Andreotti, 2015. p. 22). Decolonization occurs via the presence, and commitment to, deeper critical analyses, elevating the connection between spiritual wellbeing and social wellbeing, as well as what John Powell (2011) calls spiritual suffering and social suffering and engaging and leading with multiple ways of knowing and being (to name a few).

While working to achieve equity within higher education, we must also acknowledge the history of higher education in the United States as a tool of colonialism and a producer of knowledge used to maintain slavery and white supremacy, not deconstruct and subvert it (Wilder, 2013). In acknowledging this history, our approach is shaped into one that strives to not just provide training as a transaction (you give us time, attention, money-we give you strategies, knowledge, solutions) but indeed to guide personal and institutional transformation so that higher education can more deeply fulfill its public purpose and generate equity and justice, instead of reinforcing inequity by elevating only a narrow understanding of what constitutes knowledge and scholarship. The E\&E Lens must also be acknowledged for its limitations, being birthed within a public bureaucracy which had to consider what politically was acceptable to include in the tool and was challenged in how to deeply include the necessary connection to spirit and spirituality. We must acknowledge our own limitations as authors. We are limited by the restricted field of vision we inherit from our socialization, privilege, and lived experiences. Finally, there are limitations to this format both the written word and limited space which do not allow us to go deeply into all of the knowledge and concepts necessary to fully implement transformative strategies centered on justice and equity.

The ELSEE, as well as key foundational assumptions of the Lens upon which it was based, prioritize the practice of a holistic worldview and frame, the representation of the Relational Worldview, embodied by many communities of color (Balajee \& Cross, 2012). This frame puts forth a vision for health that incorporate all aspects of life (the physical, emotional, mental, contextual [socioeconomic, cultural, family, experience with oppression, etc.], spiritual [connection to wholeness, sense of purpose and meaning, what brings breath]), and promotes a way of being that emphasizes balance, sustainability, and spirit-led practice.

The purposes of this piece are to: (a) provide a counter-story to racial equity education based in colonized practices; (b) share a working case-study of a growing transformative racial equity effort in higher education; (c) show how other ways of knowing and being can be embodied in academic spaces; (d) elevate belonging, mindfulness, decolonization, integrity, spirit-led practice, and transparency.

To these ends we have chosen a more conversational tone for this article, one that values the use of first person, and one that reads as if we were in the room speaking with each you. Throughout this piece, we also highlight how we have used multiple perspectives and methods of communication that prioritize visual and inward communication and reflection (De Oliveira Andreotti, 2012). We also will "lift the pedagogical veil," (Balajee \& Todd, 2016) a term we coined but very much influenced by bell hooks (1994), to not just share our learnings but share why we are sharing them in the way we are and the reasons behind those choices. 
We invite you to sit with multiple, at times conflicting, ideas and allow them all to be true and not true simultaneously. We invite readers to engage with multiple forms of media for making meaning, including art, both verbal and nonverbal expression, ritual, and text and open this piece with these acknowledgements as a way of both maintaining the humility necessary to do the work of racial justice, and embody multidimensionality (De Oliveira Andreotti, 2015. p. 25 \& 27). As authors, we are not experts, only conduits for sharing experiences we have had facilitating institutional change efforts within higher education. We invite you to critique us, challenge our assumptions (and yours), and hold our truths even when (especially when) they disagree with yours. We invite you in.

\section{Sonali's Story: What the Lens is and is not, History of the Lens}

The E\&E Lens was borne as part of an emerging field of racial equity analyses and transformational initiatives within local governments. Fifteen to twenty years ago, public health departments such as those based in Louisville, KY, and Boston, MA, began to conduct equitybased mapping in their communities according to zip code. The mapping confirmed that life expectancy varied in many places by zip code, and that decreased life expectancy could also be connected to the conditions in which people are born, grow, live, work, and age, also known as the social determinants of health (Balajee, 2012 pp. 6-7 \& p. 54). These social factors or determinants are largely responsible for systemic inequities, which are unfair, avoidable, and represent systemic differences in population outcomes.

In 2008, the Multnomah County Health Department (based in Portland, Oregon) joined other jurisdictions that had already begun this work by officially investing in and carrying out a Health Equity Initiative, heavily focused at the time on creating an Equity Impact Review Tool (EIRT) that measured the impact of decisions towards equity, conducting 'Undoing Institutional Racism' training sessions for leadership, and conducting a baseline assessment of current equity efforts in all departments (Multnomah County Health Equity Initiative, 2009).

I became Program Manager of HEI in 2009; between 2009 and 2011, the development, piloting, and implementation of an EIRT was my primary focus of work. While leadership supported the creation of such a tool and put forward initial resources to staff the effort, the organizational culture did not support the actual conditions necessary for mindful decision-making, datagathering, analysis, and follow-through. Instead, speed, efficiency, and brevity in the use of such a tool and treating the whole process as a "checklist" were valued, resulting in several initial failed attempts to achieve more racially just outcomes and outputs. What saved this effort was the intentional public outreach done by a key department leader, who offered to invest time, energy, and resources into doing a deeper dive, to pilot the EIRT in a more meaningful way. This deeper dive, protected by an authentic champion in leadership, was conducted by working in three more pilot projects with "early adopters," using an expanded version of the EIRT, providing greater staff support in facilitating equity-based conversations around the use of the tool, and having an evaluator document and analyze the process, identify what was missing, find where harm was being perpetuated, and determine what worked well to get at different results.

At the same time, I began to engage leaders from communities of color and other experts from various disciplines. The leaders from communities of color told me that they didn't see their 
values, their models, and practices reflected in the tool. Mental health professionals from Portland State University also critiqued the work, saying that there was no mention of mental health as an outcome, nor was it considered to be a real impact of unjust and unfair decisionmaking processes and practices (Balajee \& Lindahl, 2012). To address these areas of critical feedback, taking the lead from Terry Cross, the now former Executive Director of the National Indian Child Welfare Association, I integrated the representation of the Relational Worldview. The Relational Worldview leads with a paradigm, outcomes, and practices calling for elevating spirit and mental well-being, alongside physical, socioeconomic, and cultural well-being when doing equity analyses (Balajee \& Cross, 2012. pp. 70-74).

The Equity and Empowerment Lens and the 2014 expanded materials (available online at https://multco.us/diversity-equity/equity-and-empowerment-lens) were created and grounded in these critiques. Multiple disciplines inform the Lens, and are included as white papers within the document such as quality improvement (Balajee \& Johnston, 2012. Pp. 79-82), mental health (Balajee \& Lindahl, 2012. Pp. 89-93), trauma- and healing-informed content (Balajee, 2014), empowerment theory (Balajee \& Wiggins, 2012), and more.

Between 2012 and the time when I left Multnomah County in 2016, the E\&E Lens was introduced and applied in a variety of settings. These included a transformative community school system, a probation program and system in the Department of Community Justice, a capital improvement plan, and more (Balajee, 2013). In the last two years of my time at Multnomah County, I and other staff began to see the need to deconstruct and revamp the Lens. We sharpened the level of analysis to include questions that sought to address where colonizing behaviors and practices existed, and emphasizing the need to integrate trauma- and healing-based approaches. Josh, in his role as Executive Director with Campus Compact of Oregon, continued to learn from me about the Lens - the most transformative ways to apply and embody it —and the ways it hindered improvement of processes, policies, relationships, and structures. In 2014, Josh decided to begin the first ELSEE cohort, and hired me to help him develop and facilitate it.

The Lens was radical at the time, for where and when it was born, but once I left government, Josh and I had the opportunity to think through how to more deeply integrate the foundational pillars of racial equity work, including decolonizing theory and practice, spirit-led strategies, racial healing, and concepts like belonging coming out of the Haas Institute in Berkeley (2016). While the E\&E Lens and other racial equity analyses, tools, and processes, help begin the conversation, analysis, and process of transformation, they can be limited by bureaucratic conditions that continue to devalue mindfulness, healing-informed approaches (W.K. Kellogg Foundation, n.d.), critical thinking, cultural responsiveness (Curry-Stevens, Reyes, \& Coalition of Communities of Color, 2014), spirit-driven practice, and addressing white supremacy culture (Okun, 2001).

We built upon what the Lens puts forward, critiqued and improved its capacity-building strategies, with colleges and universities as part of the group learning process, and strove to integrate mindfulness and spirit-led discussion and practice as much as possible. What we have found in ELSEE, and what I have found in my numerous years doing equity work within government, is that what people have stated they have feared or actively disengaged with the most (integrating reflection, mindful and spiritual practice, critical analyses, and fellowship), 
they end up yearning for and benefiting from the most. With this in mind, the ELSEE was created and started from a place of deep integration between mind, body, spirit, and environment.

\section{Campus Compact of Oregon's ELSEE, adaptation from government to higher education}

Campus Compact of Oregon is part of the national Campus Compact movement which has worked for 31 years nationally and 21 years in Oregon to support higher education institutions to more fully live out their public purpose through the advancement of community engaged learning, civic engagement, and service. As part of Campus Compact of Oregon's new strategic plan, launched in July of 2014, the compact sought ways to support member institutions' efforts to improve their programs, practices, and policies to address educational inequities. The first significant investment was the creation of the ELSEE as a neutral convener of public and private institutions, as well as 2-year and 4-year institutions. This year-long, cohort-based, professional development series was created to help institutional teams develop a more nuanced understanding of race, racism, power and privilege as it impacts and shapes student and staff outcomes, and to provide training on how to apply an equity lens to institutional decision-making to prevent further harm and improve outcomes for students, faculty, and staff of color.

We created an application which incorporated a shortened version of an organizational assessment for equity created by the Coalition of Communities of Color (2014) in partnership with Ann Curry-Stevens at Portland State University. We required that the teams include at least one staff at the Vice-President/Provost level or higher, who had authority to create institutional change, and at least one student-facing member who knew the lived experience of students of color and first-generation students on campus. Much to my surprise half of our member institutions applied (we had 20 members at that time). We created a learning cohort of 8 institutions and within the cohort were seven presidents.

The first cohort was made up of Chemeketa Community College Yamhill Valley Campus (led by Campus President Jim Eustrom), Marylhurst University (led by President Melody Rose), Pacific University, Portland Community College (including all four campus presidents Suzanne Johnson and then Lisa Avery, Sandra Fowler-Hill, Karin Edwards, and Jessica Howard), Portland State University, Southern Oregon University, Umpqua Community College, and Warner Pacific College (led by President Andrea Cook). We would go on to host a second cohort, which launched in September of 2016. This cohort included Blue Mountain Community College (led by President Cam Preus), Chemeketa Community College Main Campus (led by President Julie Huckestein), Concordia University-Portland, Mt. Hood Community College (led by President Debra Derr), Oregon Coast Community College (led by President Birgitte Ryslinge), and Warner Pacific College (back for a second year with an all faculty team). At the time of this writing, the members of the third cohort are preparing to go into retreat. These include Green River College (led by President Suzanne Johnson), the Oregon Higher Education Coordinating Commission (led by Executive Director Ben Cannon), Mt. Hood Community College (led again by President Debbie Derr), Warner Pacific College (back for third year with a team of student services staff), and Willamette University.

Grounding the series in the Lens provided a rich foundation for the work but also unique challenges in translating a tool intended for government into one focused on higher education. In 
my experience, government tends to elevate technical skills and prioritizes results and action over scholarship and knowledge creation. The Lens, as it was created, provides many tools for bureaucrats to analyze decisions and critique investments and has several white papers which describe foundational assumptions and paradigms. However, in a higher education setting these would not be considered scholarly, peer-reviewed publications. Co-founder of Black Lives Matter, Alicia Garza, has often stated the importance of both good theory and good action in the work of racial equity, and the connection between the two (2016). We have found through our years of practice that the former, theory and concepts, is often not given the necessary time and space to develop; government most often prioritizes what is deemed as 'strategy' or 'action'. Equity analyses and reflections call for a critical inquiry-based approach that seeks to identify, unearth, address, and heal root causes of racial inequity and suffering, while enhancing and promoting creative alternatives that bring about greater wellbeing and health (Johnstone \& Macy, 2012). Being able to address such root causes in their various manifestations requires strong theoretical understandings; conversely, being able to put forward alternative practices and strategies requires a similar grounding in key principles and practices.

Another serious hurdle we faced was owning our own knowledge and wisdom we had developed over almost two decades in this work because of the cult of expertise and credential that exists within higher education. Neither Sonali nor I hold doctoral degrees. Sonali has accepted a label given to her by others as a public intellectual (who ascribes to non-traditional methods of learning and knowing) but I spent most of my career in community organizing and youth development actively rejecting any attribution of myself as an academic. Yet I found myself the Executive Director of a network of higher education institutions about to lead a year-long professional development series on equity for highly educated academics.

In journaling (one form of mindfulness practice), I was struck by how much I had internalized the way that we needed to "teach" because we were working with a higher education audience. In government and community work I could be funny and casual but somehow as we approached the ELSEE that felt unprofessional. I realized how I defined knowledge and what knowledge was valuable had been colonized. I had one narrow definition of valued knowledge. Sonali understood deeply the need for us to incorporate both scholarly journal articles but also blog posts, art, imagery, music, movement, and meditation. When we sat down to plan our first session of ELSEE, Sonali said firmly that we had to open the day with a meditation and that we would meditate throughout the day together. I worried that we had seven presidents in the room and if I asked them to take deep breaths and meditate as part of a professional development session that not only would they not take the rest of the content seriously but that it could jeopardize their membership in Campus Compact.

Sonali won the day with the simple argument—we know mindfulness is required; how can we do the heavy lifting of equity work if we don't build that muscle? We did meditate, and continue to at every ELSEE session, multiple times per session, and in fact it was the presidents who most frequently said that was one of their favorite parts of the ELSEE. They so infrequently have time to take a breath - to reflect deeply, deliberately, slowly, and with intention on something. The thing I most feared became what they cherished and most needed. It took being vulnerable for that to happen, on our part and theirs. Vulnerability is critical to achieving equity. 


\section{Lessons Learned}

We gleaned rich data from these first two ELSEE cohorts, as we lived out the struggle to embody racial equity and empowerment principles, apply a decolonizing lens to our content and processes, and integrate more spirit-driven and mindfulness practices. The following are a few of our key learnings here;

It's not [just] about the quick fixes. Applying an equity lens is a long term, iterative quality improvement process not a quick fix or one-time intervention. While there are many shorter-term strategies that need to occur, addressing the root causes of racial inequities demands a more holistic, planful, and systemic approach. Shorter-term strategies need to be set in context within this larger frame, and additionally analyzed for how they perpetuate the very issues we seek to dismantle and interrupt. The language of "quick fixes" or "quick wins” has also been used as a way to settle for more "Band-Aid" types of strategies, and keep the focus away from identifying deeper issues of power, and the perpetuation of white supremacy. We have to develop a tolerance for process and a willingness to go slowly. Inequities have developed from hundreds of years of violence, ignorance, and neglect. To think we can fix them within a 5-year strategic plan is hubris at best and foolishly naive at its core.

Racial equity and empowerment require the practice and integration of mindfulness practices. To effectively work toward racial justice in any field we believe it is essential to practice mindfulness (Chodron, 2013). We must develop the skills necessary to see our own thoughts, as they are happening. To witness our thoughts before or in the process of creating emotion and be able to choose our response instead of just reacting is what we mean by mindfulness and can include meditation, connecting with nature, self-reflection, journaling, or artistic expression in many forms. Mindfulness practiced at the individual level (reflection, spirit-led work, breath work, meditation, silence, arts creation, etc.) and at the institutional level (group and team reflection, equity analyses, etc.) bring about greater focus, resiliency, attention to and willingness to make the deeper more transformative shifts necessary to bring about sustained change (Johnstone \& Macy, 2012. pp.28-33). Mindfulness can also happen at both an individual and institutional level and at its core the E\&E lens is just that, an institutional meditation. In living systems, there is a converse relationship between tension, and the ability to receive vital information (Butler-Detman, 2017). In groups, teams, interpersonal relationships, and within individuals themselves, mindful approaches and strategies can help ease and even prevent tension, allowing for necessary information (both quantitative and qualitative) to enter, be meaningfully considered, and to positively lead to more just decision-making.

A commitment to developing a more nuanced understanding of race, racism, power, privilege and whiteness is required, at each of the various levels these exist (individual/ interpersonal, institutional, community, systems). To do this work requires a deep dive into the scholarship of critical race theory, especially for white participants for whom conversations about race and racism have for too long been seen as issues for people of color. Understanding whiteness, how and why it is created and maintained, and centering ourselves in why this work matters to us and how racial inequities harm us is central as is decentering whiteness so that other ways of being and knowing can be highlighted, elevated, and celebrated. 
Expect resistance to the work and expect it to look differently for participants who are white and those who are people of color. Over the many years we have engaged in institutional change efforts we have seen consistent and predictable resistance to the work of advancing equity and racial justice. We have also developed a partial framework (see Table 1) for how this resistance shows up based on our positionality (placement within the constructed social/racial hierarchy):

Table 1: Resistant responses to the work of engagement

Dominant Culture

- Disillusionment: 'been there, done that'

- Discomfort v/s safety

- Cult of expertise, devaluing lived experience

- Focus on action-More is more

- Invulnerability-Shut down
Targeted Identities

- Disillusionment: You can't \& won't understand

- Engagement vs Trauma

- Tone Policing or Minimization

- Focus on action-More is more

- Invulnerability- Protection

When asked to engage in this work, white participants can respond with disillusionment that boils down to "I already took that diversity class once, I know all this" but for people of color who have engaged in this work for years the disillusionment comes from engaging in efforts where colleagues bring ignorance or outright disbelief that these issues of inequity are even real. We haven't found clear solutions to disillusionment. People have to be willing to engage but tapping into metaphor, narrative, movement, and art seems to spark renewed engagement.

This connects to the next form of resistance which is framed very well by Robin DiAngelo's concept of "White Fragility" (2011) where discussing issues of race makes people feel uncomfortable but what they share is that they are feeling unsafe. The lack of confidence and experience talking deeply about racism feels unsafe and those who force the conversation are creating "unsafe environments" when really it is perfectly safe just deeply uncomfortable. For folks of color, though, they must choose when they engage to expose themselves to further trauma, microaggressions (Sue, 2007) and pain so resistance can be a reasonable avoidance of further trauma. The importance of a multicultural training team is critical here. I can say things to white people that Sonali would get push back on. Sonali can say things to people of color that is trusted and heard differently than when it come from me as a white man.

Another form of resistance from dominant culture perspectives can be the cult of expertise which devalues knowledge and lived experience based on the credentials the speaker holds or even where the credentials come from ("oh, you got your degree at XYZ college, I wonder what a scholar with a more rigorous academic background might say about your findings...”) for targeted identities the resistance can come in the form of tone-policing or minimization. Being accustomed to combatting flat-out racist or uninformed thinking, we can attack an idea before deeply engaging it because it is presented in a way that triggers those past experiences. We can also choose to go along to get along and mask our own unique perspective and lived experiences 
because we don't believe they will be valued by the institution, a process called minimization (Hammer, 2008; Okun, n.d.).

One form of resistance shared by both is also a manifestation of white supremacy culture- a focus on action, more is more (Okun, n.d.) So many participants will resist a call for spiritguided practice, mindfulness, or other decolonizing practices with requests for checklists or "deliverables" and evaluate efforts as just a "bunch of talking." It takes courage and institutional will to avoid this trap. In both cohorts of the ELSEE usually by the third session there would be calls for us to move into "action.” The challenge is understanding that reflection, analysis, and meditation are the "work."

Finally, and probably the most detrimental form of resistance, is invulnerability. As we mentioned, vulnerability is crucial if we are going to create change. For dominant culture participants, when things get too hard vulnerability looks like complete disengagement and shutting down (Brown, 2012). Participants may stop responding or they may "vote with their feet" in which they stop attending sessions or have schedule conflicts come up when meetings have been planned. For participants from targeted identities, invulnerability can be a form of protection. To be vulnerable is to open up to the possibility of being harmed. For many people who have experienced multiple, recurring harms from racism and white supremacy, selfprotection can be a reasonable and expected form of resistance. The moments of "spiritual hydration" and going slow are required to be able to sit with these painful moments. These are just some forms of resistance we have witnessed. We invite you to consider in a quiet moment how have you experienced these and demonstrated resistance in the past.

Lifting the pedagogical veil/breaking down hierarchy: We have talked about how we lift the pedagogical veil in our training by inviting the participants into our thought process and sharing with them the choices we made before they entered the room. This helps to dissolve some (though not all) of the hierarchal power inherent in the facilitator/trainee dynamic. It is also a way to model teaching techniques which can create more dynamic and equitable classrooms (Hooks, 1994). Additionally, requiring ELSEE teams to have both an upper executive-level staff (many times the President) and a student-facing staff member was intentional and a powerful strategy. In institutions, moving towards racial equity requires multi-disciplinary and multi-level teams (Balajee, 2012. Pp. 18-19). This helps break down hierarchical silos, and also drives the effort to be accountable to multiple perspectives. This helped inform leaders with the knowledge of the lived experience of students and those without positional authority became more involved and felt uniquely valued. It created opportunities for rhetoric and reality to be bridged.

\section{Arts Engagement Shifts How We View Knowledge}

Art has the power to help us undo harmful ways of relating to each other. It allows us to not only value certain perspectives over others, but also promotes multiple voices and forms of wisdom to inform our efforts. When deliberately curated art can help us lead with voices that speak truth to power, decentering paradigms of conquest and assimilation, and may not be present or as present in formal academic literature. Yinka Shonibare's work, The British Library (2014) viewable at https://www.turnercontemporary.org/exhibitions/yinka-shonibare-mbe, does both. His work includes 6000 books, covered in colorful wax fabric (seen as a symbol of pride in parts of 
Africa), with each book spine holding the name of an immigrant to Britain, poignantly highlighting the multiple voices that did, indeed, contribute to British society. In this stunning work, he helps us view 'knowledge production' in a different and necessary light, helping us recognize and realize that this vast society that has colonized so many would benefit from leading with and not subjugating the myriad of voices who have tirelessly made contributions through the years. We invite you to sit with this work and reflect on the following: Where do I contribute to holding one form of knowledge more valuable over another? How can my institution or group incorporate multiple paradigms and voices in curriculum /instruction/administration? What do I feel when I view this work?

\section{Conclusion}

Over the course of the past two and half years, Campus Compact of Oregon's Executive Learning Series on Equity \& Empowerment has endeavored to move the conversation about improving outcomes for faculty, staff, and students of color into new and deeper territory. The systems and structures which generate and maintain inequity must be challenged. Higher education as a sector was built by and on these systems and structures so if, as a sector, it is committed to advancing equity and justice, a grand reimagining of higher education must happen. The ELSEE and the Lens which it is built on, propose just one approach and working model to reimagine higher education,one grounded in spirit-led practice, infused with art, breath, music, and silence,dependent on developing the skill of multi-dimensionality, and one which models, supports, and promotes a holistic vision of health. The work necessary to see true improvements on equity must be at a personal, institutional, community, and systemic level.

Through the ELSEE we have learned that the work cannot only focus on quick fixes and tangible results but must invest in transformative ways of engaging which ask us to change not just what we do but how we do it and how we do it together. We must do better on developing what France Winddance Twine calls racial literacy (2004), so all faculty, staff, and students understand race, racism, power, privilege, and whiteness, using the scholarship of critical race theory as a guide. We must expect resistance and understand where and why it manifests. We must incorporate mindfulness and meditative practice into both our individual lives but also our institutional structures so that we can more fully and clearly see ourselves, our thinking, and our reactions which all lead to our policies, practices, and programs. We must work to break down hierarchy, if not in institutional structure, then in institutional practice, so that all within our college and universities can bring their full selves to the task of achieving equitable educational outcomes and racial justice. We have to continue learning, the journey is never done. Equity is an iterative and nonlinear process of quality improvement, which includes problem definition, analysis, reflection, action, and evaluation and can be maddeningly complex. We invite you to share your thoughts and learnings with us as we all work towards a transformed academy that promotes equity, justice, and holistic wellbeing for all. We hope to partner with you in this cycle because in the words of James Baldwin (1962) “.... higher level of consciousness among the people is the only hope we have, now or in the future, of minimizing human damage.” 


\section{References}

Balajee, S. S., et al., (2012). Equity and empowerment lens (racial justice focus). Retrieved from https://multco.us/diversity-equity/equity-and-empowerment-lens

Balajee, S.S. \& Cross, T. (2012). Relational worldview model. Equity and empowerment lens (racial justice focus). pp. 70-74.

Balajee, S. S. \& Johnson, R. (2012). The lens as a quality improvement tool and process. Equity and empowerment lens (racial justice focus). pp. 79-82.

Balajee, S. S. \& Lindahl, K. (2012). Positive mental health and equity. Equity and empowerment lens (racial justice focus). Pp. 89-93.

Balajee, S.S. \& Wiggins, N. (2012). Empowerment theory and practice. Equity and empowerments lens (racial justice focus). pp. 75-78.

Balajee, S. S. (2014). Equity and empowerment lens logic model. Portland, OR: Multnomah County. Retrieved from https://multco.us/diversity-equity/equity-and-empowerment-lens

Balajee, S. S., \& Todd, J. Personal communications. September 16, 2016.

Baldwin, J. (1962). The creative process. In John F. Kennedy Center for the Performing Arts (Ed.), Creative America (pp. 17-21). New York, NY: Ridge Press, Inc.

Baltimore Racial Justice Action. (n.d.) "Why we caucus.” [blog post]. Retrieved from http://bmoreantiracist.org/why-we-caucus.

Brown, B (2012). Daring greatly. London, England: Penguin Books.

Butler-Detman, L. Personal communications. "Connections between Alexander Technique and Social Justice.” June 25, 2017.

Chodron, P. (2013). Living beautifully with uncertainty and change. Boston, MA: Shambala Publications.

Coalition of Communities of Color \&All Hands Raised. (2014). Tool for organizational selfassessment related to racial equity [Assessment Rubric]. Retrieved from http://www.coalitioncommunitiescolor.org/research-data-tools/cccorgassessment

Curry-Stevens, A., Reyes, M.-E., \& Coalition of Communities of Color. (2014). Protocol for culturally responsive organizations. Portland, OR: Portland State University Center to Advance Racial Equity. 
De Oliveira Andreotti,V. (2012). Editor's preface: HEADS UP. Critical literacy: Theories and practices, $6(1), 1-3$

De Oliveira Andreotti, V., et al. (2015). Mapping interpretations of decolonization in the context of higher education. Decolonization: Indigeneity, Education, and Society, 4(1), 21-40.

DiAngelo, R. (2011). White fragility. International journal of critical pedagogy, 3(3), 54-70. Retrieved from http://libjournal.uncg.edu/ijcp/article/download/249/116

Garza, A. (2016, February). Lecture presented at Portland State University Martin Luther King Jr. Tribute. Portland, OR.

Haas Institute for a Fair \& Inclusive Society. (2016). Othering and belonging conference. [Video highlights]. Retrieved from http://conference.otheringandbelonging.org/.

Hammer, M.R. (2008). The Intercultural Development Inventory (IDI): An approach for assessing and building intercultural competence. In M.A. Moodian (Ed.), Contemporary leadership and intercultural competence: Understanding and utilizing cultural diversity to build successful organizations. Thousand Oaks, CA: Sage.

https://doi.org/10.4135\%2F9781452274942.n16

Hooks, B. (1994) Teaching to transgress: Education as the practice of freedom. New York, NY: Routledge. https://doi.org/10.4324/9780203700280

Johnstone, C., \& Macy, J. (2012). Active hope. Novato, CA: New World Library

Multnomah County Health Equity Initiative. (2009). Health equity initiative report. Portland, OR: Multnomah County. Retrieved from https://multco.us/file/29230/download.

Okun, T. (n.d.). White Supremacy Culture. Changework dismantling racism workbook. Durham, N.C. Retrieved from http://www.cwsworkshop.org/pdfs/CARC/Overview/3_White_Sup_Culture.PDF

Powell, J. (2011). Racing to justice. Bloomington, IN: Indiana University Press.

Shonibare, Y. (2014). The british library. Retrieved from

https://www.turnercontemporary.org/exhibitions/yinka-shonibare-mbe

Sue, D. W., et al. (May-June 2007). Racial microaggressions in everyday life: Implications for clinical practice. American Psychologist, 62(4), 271-286. http://dx.doi.org/10.1037/0003$\underline{066 X .62 .4 .271}$

Wilder, C. S. (2013) Ebony and ivy: Race, slavery, and the troubled history of America's universities.: New York, NY: Bloomsbury Press. 
Winddance Twine, F. (2004). A White Side of Black Britain: The Concept of Racial Literacy, in Ethnic and Racial Studies,. 27(6), 1-30. https://doi.org/10.1080/0141987042000268512

W.K. Kellogg Foundation. (n.d). Retrieved from https://www.wkkf.org/what-we-do/racialequity/truth-racial-healing-transformation

Yatchmenoff, D. (n.d). Intro to trauma informed care. [Powerpoint presentation]. Retrieved from, https://traumainformedoregon.org/wp-content/uploads/2014/10/Intro-to-Trauma-InformedCare.pdf 


\section{Author Information}

Sonali Sangeeta Balajee is a national and international consultant on transformative practices in equity and racial healing, and Senior Fellow through the Haas Institute, UC Berkeley. Sonali led innovative racial equity and justice initiatives in local and national-alliance-building governmental projects for 13 years, including serving as lead author of Multnomah County's Equity \& Empowerment Lens with a racial justice focus, which describes how to apply equity and empowerment principles to projects and practices in various sectors.

Sonali Sangeeta Balajee

Senior Policy Fellow

Haas Institute at University of California: Berkeley

Independent Consultant

Email: sonali.s.balajee@gmail.com

*Joshua Todd is Campus Compact of Oregon's Executive Director and an adjunct professor at Portland State University. Mr. Todd worked within government for 12 years as a youth organizer and policy advisor for the City \& County of San Francisco and Multnomah County, Oregon. Mr. Todd brought his experience training on issues of racial justice and equity to Campus Compact four years ago to help improve institutional practices, policies, and ways of being that support equity.

Joshua L. Todd

Executive Director

Campus Compact of Oregon

620 SW 5th Avenue, Suite 910

Portland, OR 97204

Email: josh@oregoncampuscompact.org

Telephone: 503-406-3575

*Corresponding author 